\title{
Management of subarachnoid haemorrhage
}

\author{
Thomas A Kopitnik, Duke S Samson
}

Overview of subarachnoid haemorrhage

The brain is unique in its structure and development. Unlike other organs, as the cerebral blood vessels penetrate the cranial cavity, the vessels form a collateral network along the base of the brain and only the smaller vessels penetrate the brain substance. The larger vessels are contained within arachnoidal cisterns, designated the subarachnoid space. This subarachnoid space is a well-formed fluid containing compartment which contains and circulates CSF. ${ }^{1-3}$ Sheets of arachnoid partition the subarachnoid space into distinct chambers which provide a fragile barrier to migration of CSF, infection, or blood, throughout the subarachnoid space. It is within this fragile network of arachnoidal reflections that subarachnoid haemorrhage may occur.

Subarachnoid haemorrhage (SAH) is a condition, not a disease, that can be produced by a multitude of aetiologies. The true incidence of SAH varies considerably on a geographic basis. In the USA, SAH is the cause of death in 16 per $100000,{ }^{4}$ while Japan reports rates of 25 deaths per 100000 people. ${ }^{5}$ On the other hand, Rhodesia reports only 3.5 deaths from SAH per 100000 people per year. ${ }^{6}$ In the 1966 Cooperative Study of intracranial aneurysms and subarachnoid haemorrhage, Locksley found $50 \%$ of 2627 subjects with aneurysmal subarachnoid haemorrhage were female. Under age 40, SAH occurs more commonly in males but after the age of 50 more commonly in females. ${ }^{7}$ In contrast to spontaneous intraparenchymal brain haemorrhage, SAH does not appear to have a consistent seasonal prevalence. ${ }^{8}$ Some authors have reported on increased incidence of SAH in the Spring and Autumn, ${ }^{910}$ while Ohno reported a peak seasonal incidence in Japan in the Winter months. ${ }^{11-13}$

The data of the Cooperative Study shows that regardless of the aetiology, SAH most frequently occurs between ages 40 and 60 , with the peak frequency between 55 and 60 years of age. The Cooperative Study also found that intracranial aneurysms were the causative factors in $54 \%$ of the initial SAH, while arteriovenous malformation (AVM) accounted for $6 \%$, and other aetiologies the remaining $40 \%$. The peak incidence of SAH attributed to aneurysm occurred at slightly older ages than that for AVM. Sixty three per cent of the first haemorrhagic episodes from
AVM occurred between ages 30 and $40 .^{14}$

A third of patients who develop SAH do so while they are asleep, while another third suffer occurrence during routine daily activities, and a third during strenuous activity. Bending and lifting activities have the highest association with SAH among those activities considered strenuous. ${ }^{14}$

Death rates from the initial haemorrhage range from 40-60\%. ${ }^{16}$ Freytag reported 250 consecutive deaths from SAH and found $60 \%$ of the deaths were immediate, $20 \%$ within 24 hours of the haemorrhage, and only $11 \%$ of the patients lived over 24 hours. ${ }^{15}$ Ruptured cerebral aneurysm is the most common cause of non-traumatic $\mathrm{SAH}$, although hypertensive SAH was the most common cause of early death in the Cooperative Study. Hypertensive SAH accounted for $52 \%$ of the deaths, whereas aneurysmal SAH accounted for $36 \%$. Ninety per cent of all patients dying within 72 hours had an intracranial haematoma in the first Cooperative Study. ${ }^{17}$

The phase I report of the 1966 Cooperative Study recorded 6368 patients experiencing spontaneous $\mathrm{SAH}$ over a period of eight years. Of these patients, $51 \%$ had cerebral aneurysms subsequently diagnosed, while the remaining patients had some other cause for the haemorrhage. ${ }^{18}$ Stehbens reviewed 11 series reported from 1950-69 and found aneurysm as the source of SAH in $18-76 \%$ of the cases. ${ }^{19}$ Other causes include trauma, cerebral and spinal vascular malformations, intrinsic and extrinsic cranial and spinal neoplasms, pathological and iatrogenic coagulopathy, collagen vascular disease, sickle cell anaemia, cerebral infarction, and drug abuse. For the purposes of discussion we will divide SAH into distinct categories of aneurysmal and non-aneurysmal SAH. Although some overlap exists in the medical management of SAH in both categories, aneurysmal SAH presents unique surgical management circumstances that will be discussed separately. We will focus the following discussion on the diagnosis and treatment of both aneurysmal and non-aneurysmal SAH.

Diagnosis of subarachnoid haemorrhage Headache is the most common clinical symptom of SAH and occurs in 85-95\% of patients. ${ }^{20-22}$ At least one third of patients with aneurysmal SAH will have a minor leak, referred to as a sentinel haemorrhage. ${ }^{23}$ The 
sentinel haemorrhage may occur hours or days before a major aneurysmal haemorrhage. Many authors have emphasised that a sudden minor, but unusual, headache may herald a haemorrhage in the near future. ${ }^{20-26}$ In 2621 cases reviewed by the 1966 Cooperative Study for premonitory symptoms, the following were present immediately before a major SAH: headache $(48 \%)$, orbital pain $(7 \%)$, diplopia $(4 \%)$, ptosis $(3 \%)$, visual loss $(4 \%)$, seizures $(4 \%)$, motor or sensory deficit $(6 \%)$, dysphasia (2\%), bruit (3\%), dizziness (10\%), and other $(13 \%) .{ }^{14-17}$ Shields noted that minor bleeds were often misdiagnosed as influenza, migraine, sinusitis, headache, stiff neck, and malingering. ${ }^{27}$ Missing the diagnosis of aneurysmal SAH may have disastrous consequences for the patient presenting with minor neurological symptoms. Kassell studied 150 consecutive patients with proven ruptured aneurysms and found that only $38 \%$ were referred to neurosurgeons within 48 hours of the first symptoms of SAH. The most common cause for referral delay was physician misdiagnosis in $37 \%$, followed by administrative referral delays in $23 \%$ of patients. ${ }^{28}$ Nearly a half of all patients with SAH enrolled in a recent international cooperative study had delays in excess of three days from onset of SAH to transfer to a neurosurgical centre. ${ }^{29}$ Delay in referral to a neurosurgical centre seriously affects patient outcome; therefore, efforts in the education of primary-care physicians towards rapid diagnosis and prompt referral seem warranted.

If a significant SAH occurs, the sudden onset of intense headache is the usual presenting symptoms, followed by pain radiating into the occipital or cervical region. As blood flows into the spinal canal, cervical pain or nuchal rigidity develops. The duration and intensity of the nuchal rigidity depends on the magnitude of the SAH, although symptoms vary between patients. Signs and symptoms similar to infectious meningitis are typically seen with $\mathrm{SAH}$, due to an inflammatory reaction of the leptomeninges to the extravasation of blood. Kernig's or Leśegue's sign may be present if substantial meningeal irritation exists.

Other symptoms of SAH include photophobia, nausea, vomiting, lethargy or altered mentation. Brief loss of consciousness occurs in most patients suffering SAH, which is followed by various levels of mentation. After the haemorrhage the patient may regain alertness and orientation, or may remain with varying degrees of lethargy, confusion or obtundation. The altered level of consciousness is related to haematoma formation, hydrocephalus, increased intracranial pressure (ICP), vasospasm, or reduced cerebral blood flow. ${ }^{30}$ Other signs of neurological involvement may include motor or sensory deficits, upper motor neuron reflex changes, visual field deficits, abnormal brainstem reflexes, or abnormal motor posturing. Unlikely causes of motor deficits include emboli from the aneurysm sac, brain com- pression by a large or giant aneurysm, or seizures. Seizures may occur at the time of SAH and occur during haemorrhage in approximately $10 \%$ of patients. ${ }^{31-34}$

Clinical signs of SAH that often accompany the presenting symptoms include mild hyperpyrexia, hypertension, and ophthalmological findings. Intraocular haemorrhages may occur in the vitreous or retina, but subhyaloid or preretinal haemorrhages are more indicative of SAH. ${ }^{35}$ Subhyaloid haemorrhages appear as bright red, sharply demarcated regions adjacent to the optic disc. Other signs may include one or more cranial nerve palsies, depending upon the location of the haemorrhage and whether it is aneurysmal in aetiology.

Cranial nerve palsies can be seen with $\mathrm{SAH}$, especially in SAH due to ruptured cerebral aneurysms. Oculomotor nerve palsy frequently occurs with posterior carotid wall aneurysms associated with the posterior communicating artery. An oculomotor nerve palsy may be seen less frequently with aneurysms of the carotid bifurcation, the posterior cerebral artery, the basilar bifurcation, and the superior cerebellar artery. Third cranial nerve palsy associated with aneurysmal SAH or direct aneurysms mass effect typically results in a dilated pupil, ptosis, or deficits in eye mobility. Compression of the third nerve within the cavernous sinus may present with a midpoint pupil secondary to compression of sympathetic fibres en route to the iris. Trigeminal nerve distribution pain can result from SAH or aneurysm compression, but is rare and more commonly seen from giant aneurysms within the cavernous sinus. Abducens nerve palsy is frequently seen following SAH and is thought to be related to increased ICP and traction on the nerve during downward brainstem herniation during the haemorrhage.

CT scanning of the brain is the procedure of choice to confirm the diagnosis of subarachnoid haemorrhage. The CT scan can demonstrate the magnitude and location of the SAH, give clues as to the probable location of an aneurysm, and assess ventricular size. The success of detecting SAH with a CT scan is dependent upon the length of time after SAH until the scan is obtained. If the CT scan is obtained within five days of the haemorrhage, the probability is high that the scan can confirm the diagnosis. Eighty five per cent of patients scanned within 48 hours of SAH and $75 \%$ of patients scanned within five days will have subarachnoid blood detectable on CT scanning. ${ }^{36-39}$

The distribution of blood on the CT scan after SAH may give an indication of the probable location of an intracranial aneurysm. The presence of acute blood within the supratentorial ventricular system is often due to SAH from a ruptured anterior communicating artery aneurysm. With focal blood within the fourth ventricle, a vertebral artery aneurysm in the vicinity of the posterior inferior cerebellar artery should be suspected. Intracerebral haematomas are not uncommon 
in aneurysmal SAH, and are most frequently seen with ruptured middle cerebral or distal anterior cerebral artery aneurysms. Inferior frontal lobe haematomas commonly occur with ruptured anterior communicating artery aneurysms and are a highly accurate CT scan finding for localising the source of the SAH. ${ }^{40}$

Fisher has developed a grading scale for the CT scan appearance of SAH dependent upon the severity and location of subarachnoid blood. ${ }^{41}$ In the Fisher grading system, Grade I had no blood detectable, whereas Grade II patients had a layer of blood less than $1 \mathrm{~mm}$ thick diffusely spread throughout the subarachnoid cisterns. Grade III patients had CT scan appearance of SAH greater than $1 \mathrm{~mm}$ thick, while Grade IV patients had intraventricular or intracerebral blood. The Fisher grading system is used to relate the amount of subarachnoid blood on a CT scan to the probability of developing delayed ischaemia secondary to vasospasm.

Visual examination of CSF obtained by lumbar puncture can confirm the diagnosis of $\mathrm{SAH}$ when the CT scan is negative. Lumbar puncture after SAH is not without risk. Duffy reviewed 54 patients who had lumbar puncture following spontaneous SAH. Thirteen per cent had significant neurological deterioration following lumbar puncture. Six of the seven patients who deteriorated had evidence of brain shifts seen on follow up CT scans. ${ }^{42}$ Because lumbar puncture carries the risk of brain herniation or aneurysm rebleeding, the procedure should only be performed if the diagnosis remains in question following the CT scan, or when CT scanning is unavailable. Lumbar puncture is also useful in ruling out infectious meningitis, which may mimic symptoms of SAH. In 1901, Sicard found that yellow discolouration of CSF after centrifugation was a reliable diagnostic sign of previous subarachnoid haemorrhage. ${ }^{43}$ The term xanthochromia (xanthochromie) was first used in 1902 to describe the yellow colour of CSF in a case of pneumococcal meningitis, and was later used in the 1920 s to refer to the colour of CSF several hours after SAH. ${ }^{44-48}$ The CSF supernatant does not demonstrate discolouration immediately following SAH, but only after red blood cells haemolyse and release oxyhaemoglobin. Xanthochromia can usually be detected four hours after SAH; it becomes maximum one week after haemorrhage, and is usually undetected at three weeks. ${ }^{49}$ If xanthochromia is present in the CSF, SAH has probably occurred. If a traumatic lumbar puncture is suspected, partial or total clearing of the CSF may occur during collection. If bloody CSF is allowed to stand undisturbed in a test tube, a clot will usually not form in CSF bloody from SAH. Repeat lumbar punctures hours following a traumatic tap will be of little diagnostic value, since blood contaminating the CSF will also show xanthochromia.

After the diagnosis of SAH has been established, patients are assigned a clinical grade based on one of the accepted grading systems. Grading systems for SAH have been reported since the 1930 s, when Bramwell graded patients either apoplectic or paralytic..$^{50}$ Botterell et al introduced a useful grading scale in 1956 which has undergone several modifications, including one in 1973 by Lougheed and Marshall. ${ }^{5152}$ One of the more universally accepted grading scales for patients with SAH is that of Hunt and Hess (1968), ${ }^{53}$ which was later modified by Hunt in $1974 . .^{54}$ This grading system classifies patients as follows:

Grade O: Unruptured aneurysm without symptoms

Grade 1: Asymptomatic or minimal headache and slight nuchal rigidity

Grade 1a: No acute meningeal or brain reaction, but with fixed neurological deficit

Grade 2: Moderate-to-severe headache, nuchal rigidity, no neurological deficit other than cranial nerve palsy

Grade 3: Drowsy, confused, or mild focal deficit

Grade 4: Stupor, moderate-to-severe hemiparesis, possible early decerebrate rigidity and vegetative disturbances

Grade 5: Deep coma, decerebrate rigidity, moribund appearance

Both Botterell and Hunt grading scales put the patient into the next worse grade if serious systemic disease or vasospasm is present. Hunt has further specified that attention to the name and date of the classification system used is important to ensure comparability of various patients or patient series reported. ${ }^{55}$

After SAH has been confirmed, four-vessel cerebral angiography should be performed as soon as possible. The angiographic investigation should visualise all intracranial vessels with multiple views and clearly demonstrate the origins of each posterior inferior cerebellar artery (PICA). We have seen SAH produced from a vertebral aneurysm arising within the cervical canal in association with an abnormally proximal PICA origin. The goals of the angiogram are to demonstrate the cause of the SAH, define the neck of an aneurysm (if possible), delineate the vessels arising adjacent to the aneurysm, determine if multiple aneurysms are present, and assess the degree of vasospasm, if present. In 1977 Nibbelink reported a significant complication rate for cerebral angiography in acute SAH. ${ }^{56}$ Complications and their frequencies were: transient hemiparesis, $2 \%$; permanent neurological deficits, $2.5 \%$; death, $2.6 \%$; worsening of ischaemic deficit, $3 \%$; and aneurysmal rebleeding, $1.5 \%$. The present complication rate for cerebral angiography should be less than $1 \%$, with an experienced neuroradiologist. ${ }^{57}$ Aneurysm rupture during angiography has been reported, but is fortunately an infrequent occurrence. ${ }^{58-60}$

MRI has not proved useful in the acute diagnosis of SAH. MRI has, however, proved valuable in the localisation of subarachnoid clot beyond the time the blood is detectable 
with CT scanning and to identify the most probable source of haemorrhage when multiple aneurysms are found on angiography. ${ }^{61}$ We have found MRI invaluable in the evaluation of SAH secondary to giant intracranial aneurysms. Giant aneurysms are often partially thrombosed and incompletely opacify with angiography. MRI is useful in demonstrating the magnitude and location of the aneurysm sac, which angiography fails to elucidate. We have used magnetic resonance angiography to follow the size of giant aneurysm, but because of resolution limitations do not use it in evaluating acute SAH.

\section{Non-aneurysmal subarachnoid haemorrhage}

Seventy five per cent of patients who suffer a spontaneous SAH will be found to have a cerebral aneurysm. ${ }^{62}$ Arteriovenous malformation (AVM) will be discovered in $5 \%$, while $20 \%$ of SAH patients will have various other causes to which the haemorrhage is attributed, or no cause found. When the initial angiogram does not demonstrate the cause of the SAH, further investigation with repeat angiography is controversial. Earlier studies found that a significant number of patients had an aneurysm demonstrated on a second angiogram or at necropsy that was not evident on the initial study. ${ }^{6364}$ As angiographic techniques have improved, the yield of repeat angiography has decreased. Forster reported only one patient in whom a second angiogram diagnosed a previously occult cerebral aneurysm out of $56 \mathrm{SAH}$ patients with initially negative studies. ${ }^{65}$ Others have reported higher diagnostic yields of $3-4 \%$, although Suzuki reported repeat angiogram diagnosed aneurysms in $22 \%$ of patients. ${ }^{66-69}$ It has been our policy to tailor each diagnostic evaluation to the patient's specific findings. If the initial angiogram fails to demonstrate a cause of the SAH, but shows focal vasospasm, the angiogram is repeated in 5-7 days. We also advocate repeat angiography if a portion of the cerebral vasculature is not adequately visualised on the initial study or in patients who have a large amount of subarachnoid blood visualised on CT scanning.

SAH is a condition, not a disease, that is not amenable to immediate intervention in order to lessen the severity of the initial haemorrhage. The management goals in spontaneous SAH are similar to those in head trauma, namely diagnose the condition and minimise the potential for further injury. Patients who present with non-aneurysmal SAH are typically in better neurological condition than those patients with SAH from ruptured aneurysms. ${ }^{70-73}$ Although the source of SAH remains undiscovered in $20 \%$ of patients, the mortality rate for this group of patients is less than $3 \%$. The incidence of rebleeding is $4 \%$ in the first six months and ranges from $0 \cdot 2-0 \cdot 86 \%$ per year after six months. ${ }^{74}$ The outcomes of a number of reported series concerning $\mathrm{SAH}$ with negative angiography have found that $80 \%$ of patients with SAH of undetermined aetiology will have a good outcome and return to gainful employment, as opposed to $50 \%$ of patients with aneurysmal SAH. ${ }^{62} 73$ The patient's clinical status usually corresponds to the amount of subarachnoid blood present on the CT scan. ${ }^{68}$ The magnitude of the haemorrhage seen on CT scan relates to the development of complications secondary to the haemorrhage. These complications frequently include cerebral vasospasm, hydrocephalus, seizures, memory disturbances, headache, and psychological disturbances. Stober has reviewed the blood distribution on CT scans following both aneurysmal and non-aneurysmal SAH and determined that SAH of unknown aetiology is unlikely to result in blood in the Sylvian or interhemispheric fissures. $^{75}$ We have frequently observed that the interpeduncular or perimesencephalic cisterns often demonstrate focal blood collections when SAH of unknown aetiology occurs.

The differential diagnoses that must be considered in non-aneurysmal SAH are extensive. Trauma is a frequent cause of nonaneurysmal SAH. It can be difficult to determine if the SAH was the result or the cause of the patient's injuries. Other causes include angiographically demonstrable and angiographically occult vascular malformations, coagulopathic conditions, granulomatous angitis, venous thrombosis, central nervous system infection, intra- and extra-axial tumours, hypertension, drug abuse, and various aetiologies within the spinal canal..$^{76-78}$ SAH of spinal origin occurs most commonly from spinal arteriovenous malformations, but may also be related to spinal neoplasms or use of systemic anticoagulants.

The treatment of SAH of unknown aetiology is aimed at preventing secondary injury and relief of symptoms. Patients are initially given bed rest with close nursing observation. Blood pressure is controlled with antihypertensives and the patients are well hydrated. Headache and cervical pain are treated with narcotic analgesics as needed and prophylactic anticonvulsants are administered. Corticosteroids in the form of dexamethasone $4 \mathrm{mg}$ every 6 hours are used to symptomatically alleviate signs of blood-induced meningitis. We also administer an oral calcium channel-blocking agent, nimodipine $60 \mathrm{mg}$ every 4 hours, to reduce the effects of cerebral vasospasm, should it occur. Other symptomatic treatment is initiated as necessary. Serial CT scans are performed daily for the first couple of days after the SAH to detect hydrocephalus or rebleeding. Hydrocephalus may symptomatically present with headache, drowsiness, confusion or agitation. The incidence of acute hydrocephalus following SAH varies extensively among reported series. Bohn and Hugosson found $1 \%$ of their patients operated on for ruptured cerebral aneurysms required shunting for hydrocephalus. ${ }^{79}$ In contrast, Modesti and Binet found a $63 \%$ incidence of abnormal 
ventricular enlargement on CT scanning within 24 hours of SAH. ${ }^{80}$ In 1985, van Gijn reported a series of 174 patients who suffered SAH. Thirty four (20\%) developed acute hydrocephalus within 72 . hours of the haemorrhage. Although intraventricular blood was closely associated with development of hydrocephalus, the extent of cisternal haemorrhage was not. The mortality rate among those patients with acute hydrocephalus was significantly higher than in those without this complication. ${ }^{81}$ If hydrocephalus develops following subarachnoid haemorrhage, clinical judgement should be used to assess the severity of the hydrocephalus and the need for CSF diversion. We have found that some patients will transiently exhibit asymptomatic ventricular enlargement following subarachnoid haemorrhage which spontaneously resolves. If the hydrocephalus causes clinical manifestations, continuous external ventricular drainage is performed until the CSF clears of haemorrhagic debris. Continuous external ventricular drainage can usually be performed with little additional morbidity or mortality. ${ }^{82}$ After the CSF clears of blood, an attempt is then made to wean the ventricular drainage by gradual elevation of the external CSF collection chamber. If patients tolerate ventriculostomy weaning both clinically and by CT scan appearance of the ventricular size, the ventricular drain is then discontinued. If the external ventriculostomy cannot be weaned without concurrent hydrocephalus, and internal ventriculoperitoneal shunt is placed.

Symptomatic vasospasm occurs in a small percentage of patients who present with SAH of undetermined aetiology. The incidence is less than in those patients found to have aneurysmal SAH, and is related to the magnitude of the haemorrhage seen on the presenting CT scan. ${ }^{67}$ We have frequently observed angiographic vasospasm in non-aneurysmal SAH, although clinically symptomatic vasospasm in this specific group of patients is rare in our experience. The treatment of symptomatic vasospasm will be further discussed in this section to follow on aneurysmal subarachnoid haemorrhage.

\section{Aneurysmal subarachnoid haemorrhage} GENERAL CONSIDERATIONS

Ruptured cerebral aneurysms constitute $77 \%$ of the cases of spontaneous SAH..$^{83}$ Chason and Hindman were able to demonstrate 137 cerebral aneurysms, a $5 \%$ incidence, in a necropsy study of 2786 patients who died of causes unrelated to SAH. They also determined that 42 per cent of the aneurysms had ruptured at some point previously. ${ }^{84}$ Necropsy studies will demonstrate a higher occurrence rate of ruptured aneurysms than clinical or radiological studies because aneurysm rupture is a frequent cause of sudden death. Although many series reflect widely variable epidemiological statistics, an approximate occurrence rate for aneurysm rupture is 10 per 100000 population per year. There is an average prevalence rate of unruptured aneurysms of $5 \%$ of the adult population.

There are three basic theories to the pathogenesis of cerebral aneurysms. One theory proposes that a congenital weakness in the muscular layer of cerebral arteries allows the intimal layer to herniate and eventually distend and destroy the elastic membrane, leading to outpouching of an aneurysmal sac. Other theories have attributed aneurysm formation to postnatal degeneration within the vessel wall that leads to deterioration of the internal elastic lamina and resultant aneurysm formation. Others have postulated that it is a combination of congenital and degenerative effects that lead to aneurysm formation. ${ }^{4}$ Aneurysms tend to occur at vascular bifurcations, although they infrequently may occur unassociated with vessel branches. ${ }^{85}$ Forbus used a rigid glass model to demonstrate that the point of greatest stress on the artery wall occurs at the apex of a vascular bifurcation in line with the direction of flow. ${ }^{86}$ The law of Laplace relates wall stress to radius and transmural pressure and can be used to show that as the radius of the aneurysm enlarges, significantly less force is required to cause further enlargement of the sac. ${ }^{87}$ The average size of ruptured aneurysms is $7.5 \mathrm{~mm}$. Two per cent of aneurysms under $5 \mathrm{~mm}$ rupture in contrast to $40 \%$ of those between $6 \mathrm{~mm}$ and $10 \mathrm{~mm}$ in external diameter. ${ }^{88}$ Sixty per cent of aneurysms discovered in people under 60 years of age have previously haemorrhaged. ${ }^{89}$ Unruptured but symptomatic giant aneurysms carry a grave prognosis related to both mass effect and future rupture. The commonly held perception that giant aneurysms do not bleed and can be managed conservatively is dangerously misleading. Between $30 \%$ and $70 \%$ of giant aneurysms that become symptomatic are associated with subarachnoid haemorrhage. ${ }^{90}{ }^{91}$ Approximately $20 \%$ of SAH patients will have multiple aneurysms. Frequent sites of multiple aneurysms are the internal carotid arteries on both sides. ${ }^{4}$ This makes it imperative to demonstrate all cerebral vessels on diagnostic angiography when SAH is investigated. The presence of multiple aneurysms will significantly affect the planning of surgical procedures aimed at aneurysm obliteration. When multiple aneurysms are present, the most proximal and the largest will be the most likely source of SAH. ${ }^{92}$ Aneurysms with small secondary outpouchings are thought to be particularly prone to rupture, and these outpouchings may actually be false sacs from previous haemorrhages. ${ }^{93} 94$ DuBoulay has hypothesised that secondary aneurysm loculations are regions where the aneurysm wall is most unstable, and found asymptomatic aneurysms rarely had secondary loculations. $\mathrm{He}$ also found the mortality rate of loculated aneurysms to be twice that of smooth-walled lesions. ${ }^{95}$

Examinations that are helpful in determining which of the multiple aneurysms is most likely to be the source of SAH, include the history of the ictal event, clinical examination, 
CT scan, angiogram, and MRI study. The patient may be able to lateralise the initial headache symptoms when bilateral aneurysms are present, and the clinical examination may demonstrate unilateral weakness or cranial nerve palsy. When multiple aneurysms are diagnosed, CT localisation of subarachnoid blood, ventricular shift, and the site of an intraparenchymal haematoma are helpful findings. Local vasospasm may be present near the ruptured lesion on angiography. The aneurysm most likely to have bled will be the largest, have the most irregular contour, or have a nipple-like secondary loculation. Nehls found statistical evidence that aneurysms associated with the anterior communicating complex, the basilar apex, and the posterior inferior cerebellar artery-vertebral junction were the most likely aneurysms to bleed when multiple aneurysms were diagnosed. ${ }^{96}$ MRI can be valuable in detecting subarachnoid clot beyond the time clot is visible on the CT scan and in localising the causative source of haemorrhage in cases with multiple aneurysms. Focal increased signal intensity is often found around a ruptured aneurysm. ${ }^{61}$

We plan the primary surgical approach to the ruptured lesion and clip asymptomatic aneurysms that are accessible through the surgical exposure. There appears to be a poorly understood phenomenon of enlargement and rupture of previously asymptomatic aneurysms in patients who undergo surgery to clip the ruptured lesion. Others have noted an increased frequency of asymptomatic aneurysm rupture after treatment of the symptomatic aneurysm as well. ${ }^{97} 98 \mathrm{~A}$ possible explanation may relate to increased haemodynamic stress in the perioperative period producing an increase in the transmural pressure gradient within asymptomatic aneurysms. Haemorrhage from a previously asymptomatic aneurysm following surgery to treat the ruptured aneurysm is an extremely rare occurrence in our practice. Others have reported that postoperative volume expansion and induced hypertension after surgery for a ruptured aneurysm are both safe and efficacious, and do not appear to promote rupture of asymptomatic lesions. ${ }^{99} 100$

After the diagnosis of ruptured cerebral aneurysm has been confirmed as the cause of $\mathrm{SAH}$, treatment plans need to be considered. The treatment for SAH secondary to a ruptured aneurysm is primarily surgical, with nonoperative treatment reserved for those patients in the poorest grades. Yasargil performed a retrospective analysis comparing surgical to nonsurgical management in patients with ruptured aneurysms in one specific region of Switzerland. Of 624 proven ruptured aneurysms, 349 (55.9\%) underwent operation with $5(1.4 \%)$ deaths. Two hundred and seventy five (44.1\%) patients did not have surgery and only $4(0 \cdot 6 \%)$ patients survived, resulting in a mortality rate of $98.5 \%$ in the nonoperated patients. ${ }^{101}$ Therefore SAH from a ruptured cerebral aneurysm has a high mortality and nonopera- tive management is rarely indicated. Expectant management should be confined to poor-grade patients who would not be expected to tolerate a surgical procedure.

Patient selection and timing of surgery are important factors that determine outcome. The dilemma of which patient should undergo surgery and when surgery should be performed, in relation to the onset of SAH or vasospasm, remains an unresolved issue. Current trends in neurosurgery and our own results support early operation in patients with good clinical grades. Early surgery is performed to secure the ruptured aneurysm, prevent rebleeding, and to remove as much subarachnoid clot as possible. We generally offer surgery to those patients in Hunt-Hass grades $^{55}$ I to III as soon as they are fully radiologically evaluated and medically prepared following hospital admission. Poorgrade patients, grades IV and $V^{55}$ are treated non-operatively until their clinical condition improves. Diagnosis and treatment of acute hydrocephalus by external ventricular drainage will often result in patients improving by one grade early after SAH. In a similar fashion, patients who are in a poor grade, but harbour a significant intraparenchymal haematoma, may show significant improvement with surgery to obliterate the aneurysm and remove the mass effect from the haematoma.

The rationale for conservative management of poor-grade patients stems from previous studies evaluating surgical results related to the patient's preoperative status. Hunt and Hess categorised patients into grades to investigate prognosis of the preoperative neurological status, and found that operative mortality approached $75 \%$ in poor-grade (grades IV and V) patients. ${ }^{53}$ The explanation for dismal surgical results in poor-grade patients is probably multifactorial. A combination of elevated intracranial pressure, reduced cerebral blood flow, poor tissue tolerance to manipulation, and poor tolerance to temporary occlusion, all contribute to poor surgical results. Some have seen encouraging results with aggressive surgical treatment of poor-grade patients, ${ }^{102}$ although our experience and that of others ${ }^{101}$ has reaffirmed that, in general, poor-grade patients have poor outcomes.

After it has been determined that a patient with aneurysmal SAH is a candidate for surgery, timing of surgery becomes a consideration. The overall management morbidity and mortality must be a consideration in the surgical planning. The major factors that must be considered are: 1) aneurysm rebleeding; 2) delayed ischaemia deficit due to vasospasm, and 3) technical considerations of the operative procedure. The predominant historical opinion has been that if surgery was intentionally delayed for 1-2 weeks following $\mathrm{SAH}$, the surgical outcomes were much more favourable compared with early surgery. Norlen and Olivecrona published the results of 100 consecutive anterior communicating artery aneurysms managed in this fashion and 
reported a remarkable $3 \%$ mortality rate. ${ }^{103}$ It was presumably conceived in these early studies that technical difficulties associated with early surgery would negate any potential benefit early surgery was affording to prevent rebleeding and facilitate the management of vasospasm. There was also concern that early surgery could worsen the effects of vasospasm in the face of disturbed autoregulation. ${ }^{104} 105$ Because of improvements in neuroanaesthesia, neurosurgical instrumentation and the advent of the operative microscope, investigators have readdressed the optimal timing of aneurysm surgery.

Recent studies investigating the timing of surgery for ruptured intracranial aneurysms have shown that early surgery was not significantly more difficult than delayed surgery from a technical standpoint, as perceived by the operating surgeons. Although the results of surgery delayed until after post-bleed day 10 were superior to results of early surgery, the morbidity and mortality of rebleeding $(12 \%$ at 2 weeks) and other complications associated with delayed surgery, negated any benefit of delaying the procedure. Early surgery did result in a decreased incidence of aneurysm rebleeding, but did not significantly affect the incidence of subsequent vasospasm. ${ }^{29106}$ The overall results of these contemporary cooperative studies show that overall management morbidity and mortality of early versus delayed surgical therapy are not significantly different. The possible exception may be the patients who were alert and in excellent grade upon admission and had the most favourable results with early surgery. The surgeon must weigh all factors, including his/her technical capabilities, the risk of rebleeding, and potential management difficulties, including vasospasm, when deciding on the best time to perform the surgical procedure.

\section{Preoperative management of aneurysmal subarachnoid haemorrhage}

We believe in early surgical repair of the ruptured aneurysm followed by aggressive medical therapy, if necessary, for vasospasm. It is preferable for referral patients to be transferred to a neurosurgical centre as soon as possible following the ictus of SAH. The thought that patients need to be observed for a period following SAH before transfer to a neurosurgical centre is an erroneous concept and only serves to delay transfer unnecessarily and place patients at risk for rebleeding. We have found that immediate transfer once the diagnosis of SAH is suspected provides the best chance for optimal patient outcome. It is imperative that pertinent radiographic studies also be sent to the neurosurgeon along with the patient. This is especially true for angiograms performed before transfer. Sending poor quality copies of radiographs or not sending the complete angiogram because of individual hospital administrative policy, results in needless and dangerous repetition of vital diagnostic examinations.
We admit patients with SAH directly to the surgical intensive care unit, where further assessment is performed. Patients are graded according to the Hunt-Hess grading sale, ${ }^{5354}$ and accompanying radiographic studies are evaluated. In the presence of obvious $\mathrm{SAH}$ on CT scan, a cerebral angiogram is immediately performed, if not previously obtained. Angiography is performed as soon as possible after admission, with each case individualised for the patient. Early angiography is beneficial for early diagnosis, even if patients are not offered immediate surgery. An angiogram obtained early after SAH will confirm the diagnosis, and preoperative planning or immediate surgery can be undertaken. Preoperative preparation usually includes routine blood tests, type and crossmatch of packed red blood cells, placement of central venous access and radial arterial monitoring catheters, and premedication.

Preoperative medication includes administration of anticonvulsants, corticosteroids, calcium channel blockers, antihypertensives and analgesics. Although we intially attempt to normalise the patient's intravascular volume status, we do not prophylactically induce hypervolaemia. Prophylactic hypervolaemia has been shown to be hazardous and offers no clear benefit. ${ }^{107}$ Strict attention to blood pressure control before aneurysm surgery has been shown to reduce the rate of aneurysm rebleeding. ${ }^{108}$ The effect of calcium channel blockers is less clear. Reports on calcium channel blockers show that prophylactic use of these agents does not prevent vasospasm, but may decrease the overall management morbidity following SAH. ${ }^{109-112}$ In the light of the referenced reports on calcium channel blocking agents, we place all patients on this drug immediately upon admission to the hospital. We have not seen a reduction in the severity or morbidity from vasospasm since we added this treatment to our management protocol. Clearly, further studies need to be performed on this important issue.

The administration of antifibrinolytic therapy designed to minimise clot lysis is controversial. ${ }^{113114}$ Epsilon-aminocaproic acid (AMICAR) is one of the more widely used antifibrinolytics which primarily functions to inhibit the conversion of plasminoid into plasmin. The main function of plasmin is to digest fibrin and aid in clot lysis. Intravenous injection of AMICAR gives a peak plasma level 20 minutes after injection, and $75 \%$ will be excreted unchanged in the urine within 12 hours. The drug crosses the blood-brain barrier and achieves maximal antifibrinolytic activity 48 hours after therapy is initiated. ${ }^{115}$ Patients who receive this therapy are given 2 grams per hour intravenously for 48 hours, then 1.5 grams per hour for the duration of therapy or until surgery is performed. Review of the 1966 Cooperative Study found a significantly decreased incidence of aneurysm rebleeding with the use of antifibrinolytics. Adams et al reported that the rate of rebleeding and death was approximately $21 \%$ at 14 days among patients treated with bed rest 
alone following SAH. The addition of antifibrinolytic therapy lowered the incidence of rebleeding and death to $10 \%$ at two weeks in those patients studied. ${ }^{116}$ Although antifibrinolytic therapy decreases rebleeding by $50 \%$ during the first two weeks following $\mathrm{SAH}$, an increase in management complications are a major concern. The most frequent complication of antifibrinolytic therapy is diarrhoea, occurring in $24 \%$ of patients. Communicating hydrocephalus is $25 \%$ more frequent with antifibrinolytic therapy according to Park's report. ${ }^{117}$ The greatest concern over the use of antifibrinolytic agents has been the associated increase in ischaemic neurological deficits, that has counterbalanced its efficacy in some studies. ${ }^{113}$ Our view is that antifibrinolytics have little role to play in acute aneurysmal subarachnoid haemorrhage if surgery is anticipated within two days of admission. These agents may be of value if an operative procedure is delayed longer than 48 hours.

Aneurysm rebleeding is a catastrophic event that may occur relatively soon after the initial SAH. ${ }^{118}$ The frequency of aneurysm rebleeding is highest within the first 48 hours following the initial SAH with an average incidence of $4 \% .{ }^{108119}$ The mortality rate from aneurysm rebleeding carries at least a $70 \%$ mortality rate. Surgical treatment offers the best protection against rebleeding and early surgery after hospital admission and affords the best chance of minimising this highly lethal complication.

Some neurosurgeons are concerned that surgery soon after acute SAH is technically difficult due to brain swelling and obscuration of vital structures by acute blood within the subarachnoid space. Despite these considerations, the majority of our patients have surgery early after SAH to minimise the incidence of rebleeding. Although the surgery can be technically more demanding, we have not found technical problems to adversely influence the management morbidity and mortality of our patients. We have found intraoperative ventricular puncture and aggressive gravity drainage of CSF to be an extremely useful adjunct in overcoming an initially swollen brain soon after SAH. ${ }^{120}$ The results of the most recent cooperative study confirm that although most surgeons report that the brain is significantly more swollen with early surgery, the majority of surgeons report that early surgery is not technically more difficult. ${ }^{106}$ In this cooperative study, early surgery did reduce the incidence of rebleeding, but had no effect in decreasing the incidence of vasospasm, which theoretically might have been expected by early subarachnoid clot removal. ${ }^{121-123}$

\section{Surgical considerations and}

\section{complications}

The goals of aneurysm surgery following SAH are: (1) aneurysm obliteration with preservation of normal vasculature; (2) minimal brain tissue disruption, and (3) removal of as much subarachnoid clot as is safely feasible. Our patients undergoing uncomplicated aneurysm repair following SAH had morbidity and mortality rates of approximately $10 \%$. When intraoperative rupture occurred, the morbidity and mortality rates increased to approximately 20 per cent. Factors such as the phase of the dissection, the use of blunt versus sharp dissection techniques, and complete aneurysm neck dissection play key roles in minimising intraoperative aneurysm rupture. Adequate depth of anaesthesia, strict blood pressure control, and appropriately situated craniotomies, which necessitate minimal brain retraction will aid in reducing the incidence of aneurysm rupture before subarachnoid dissection.

The most frequent time for intraoperative aneurysm rupture is during subarachnoid dissection before clip application. ${ }^{124-126}$ In our experience, ill-advised blunt dissection techniques are the most frequent cause of intraoperative rupture. Aneurysm rupture produced by blunt dissection typically produces a large tear at the aneurysm sac-neck junction, and the amount of bleeding is usually torrential. This is in contrast to aneurysm bleeding resulting from sharp dissection. Bleeding from sharp dissection is usually punctate and more controllable than bleeding from blunt dissection. The dense clot surrounding the vessels and the aneurysm should be sharply divided with microscissors or microarachnoid knives. Dissection should also follow the normal vasculature when dissecting into the vicinity of the aneurysm. Proximal and distal vascular control early in the dissection and before aneurysm dissection is mandatory in all cases. Definitive neck dissection before aneurysm clip application will also reduce the likelihood of clip-induced rupture of the aneurysm, which is similar to aneurysm rupture from blunt dissection.

Intraoperative aneurysm rupture is an inevitable complication of intracranial aneurysm surgery. Close blood pressure control, basal craniotomy flaps, minimal brain retraction, strict use of sharp dissection techniques, dissection along normal vascular anatomy, and appropriate use of available clips, can potentially minimise the incidence of intraoperative rupture and provide the optimal chance for a good surgical outcome.

In the event of intraoperative aneurysm rupture, we have found several techniques useful. Temporary arterial occlusion on all afferent and efferent vessels involved with the aneurysm, is one of the most useful measures. We induce electroencephalographic burst suppression during temporary occlusion to optimise cerebral protection during temporary occlusion. We use etomidate for cerebral protection because of its ability to suppress cerebral metabolic activity and oxygen requirements, its rapid reversibility, and minimal toxicity. ${ }^{127}$ We do not use induced hypotension to control intraoperative aneurysm rupture because of the theoretically deleterious effects of hypotension on patients specifically susceptible to either acute or delayed 
ischaemia. Giannotta found that induced hypotension influenced outcome negatively when used to control intraoperative aneurysm rupture. ${ }^{126}$

We attempt to remove as much subarachnoid clot during surgery as is deemed safe. The variable consistency of acute and subacute subarachnoid blood at various stages of fibrinolysis renders success of clot removal unpredictable. Previous reports have found some potential benefit in preventing vasospasm or lessening its severity by aggressive subarachnoid clot removal. ${ }^{128129}$ Recent reports have focused on the use of topical thrombolytic agents instilled into the subarachnoid space during surgery. The chief agent being investigated is tissue-type plasminogen activator (tPA) substance. Use of tPA has been reported to show some effect on chemical thrombolysis of subarachnoid clot in the postoperative period..$^{130-133}$ In our limited experience, tPA does appear to aid clearance of subarachnoid blood seen on CT scan. Whether this chemically induced thrombolysis will be beneficial in decreasing the morbidity and mortality of vasospasm remains to be demonstrated. The addition of TPA at surgery carries some risk of increased bleeding in the operative site postoperatively.

\section{Postoperative management}

Patient care following surgery to obliterate a ruptured cerebral aneurysm is complex and must be based on many possible complications. The major problems in the immediate postoperative period include brain swelling, bleeding in the operative site, fluid and electrolyte disturbances, hydrocephalus, and the onset of cerebral vasospasm. Close observation is necessary because most postoperative complications produce similar symptoms but require entirely different treatment. As well as the neurological examination, frequent CT scanning, blood electrolyte determination, and transcranial Doppler (TCD) evaluations are particularly helpful.

Patients who have had surgery to repair a ruptured aneurysm are predisposed to develop brain swelling and oedema. The subarachnoid clot is irritating to the brain surface, cerebral vascular autoregulation is disturbed, intracranial pressure is often elevated, and regions of infarction related to surgical occlusion are all contributing factors to postoperative brain swelling. Patients are typically maintained on dexamethasone, $16 \mathrm{mg}$ per day, for at least one week postoperatively. Intravascular volume status is closely assessed with either central venous access monitors or pulmonary artery catheters, depending on the patient's condition. At the time of surgery the degree of swelling and the necessity of frontal or temporal lobectomy are assessed. In a similar fashion, lobectomy is considered postoperatively if clinical deterioration occurs concomitant with CT evidence of brain swelling.

Fluid and electrolyte disturbances are also relatively common following SAH and surgery to repair a ruptured aneurysm. Takaku found an $8.8 \%$ incidence of electrolyte disturbances following aneurysm surgery. ${ }^{134}$ Hyponatraemia is the most common abnormality, occurring in $53 \%$, whereas hypernatraemia had the highest mortality rate (42\%). Hyponatraemia can be due to either inappropriate secretion of antidiuretic hormone or true natriuresis due to cerebral salt wasting. Both syndromes are characterised by a decrease in plasma sodium levels and osmolality, associated with increased urine sodium concentration greater than $25 \mathrm{mmol}$ per litre. Clinical differentiation of these syndromes is important because patients with primary salt wasting syndrome are hypovolaemic and require sodium and fluid replacement. Conversely, true inappropriate antidiuretic hormone secretion is treated with fluid restriction.

As previously discussed, communicating hydrocephalus both before and after surgery can be seen in SAH patients. There have been some reports that early operation and subarachnoid clot removal may decrease the incidence of postoperative hydrocephalus. ${ }^{135}$ Others have proposed that preoperative antifibrinolytics contribute to the development of hydrocephalus. ${ }^{17}$ Regardless of the cause, postoperative hydrocephalus should be ruled out in any patient with a decline in mental status following aneurysm surgery.

Delayed ischaemic deficit secondary to cerebral vasospasm is the greatest cause of morbidity in patients surviving the initial SAH. Clinically significant vasospasm occurs in $30 \%$ of patients with SAH from a ruptured cerebral aneurysm. Permanent neurological deficit or death occurs in approximately $12 \%$ of patients who develop severe clinical vasospasm. ${ }^{136} 137$ Cerebral vasospasm has a peak incidence around the sixth to eighth day following $\mathrm{SAH}$, although it can occur at any time following SAH up to about 14 days post-bleed, beyond which it is extremely rare. ${ }^{138}$ When vasospasm develops, it may last for several days or up to several weeks. ${ }^{136} 139$ The most reliable predictor of those patients predisposed to develop vasospasm is the amount and distribution of subarachnoid blood on the CT scan. Thick layers of blood in the basal cisterns carries a higher risk of vasospasm than diffuse or focal loculations of cisternal blood. Lobar haematomas and interhemispheric blood are associated with a low risk of vasospasm. Subarachnoid blood in the Sylvian fissure appears to carry an intermediate vasospasm risk. ${ }^{140}{ }^{141}$ Clinical vasospasm develops gradually over hours or days, and is typically associated with gradual, progressive decline in neurological status. Headache, fever, and leukocytosis are often present and may herald the onset of vasospasm before neurological deterioration.

At present, the mainstay of treatment for clinically significant cerebral vasospasm is the induction of hypervolaemia and systemic hypertension, often referred to as hyperdynamic therapy. The neurological deficits seen with vasospasm are the result of arterial 
narrowing and increased cerebrovascular resistance. Because autoregulation is usually impaired after SAH, manoeuvres that increase cerebral perfusion pressure can increase cerebral blood flow in the ischaemic regions. ${ }^{142143}$ Patients undergoing induced hypertension and intravascular volume expansion are best treated in an intensive care unit with arterial and deep venous pressure monitoring. An indwelling arterial catheter is used for close blood pressure monitoring, and a Swan-Ganz catheter is used to monitor pulmonary capillary wedge pressures. Transcutaneous pulse-oximeters are used to monitor oxygen saturation and signs of early pulmonary decompensation from hypervolaemic therapy. Fluid balance is assessed hourly, and daily chest radiographs are performed and inspected for signs of congestive heart failure or pulmonary oedema.

The initial therapy for symptomatic vasospasm consists of volume expansion with plasma protein fractionate to create a positive fluid balance of 1-2 litres. The pulmonary artery wedge pressure is usually maintained between 18 and $20 \mathrm{mmHg}$, and the central venous pressure is kept at approximately 10 mmHg. If clinical improvement is not seen soon after volume expansion, arterial blood pressure is elevated with dopamine and typically maintained with systolic pressures between 180 and $220 \mathrm{mmHg}$. Kassell has reported 58 patients treated for cerebral vasospasm with volume expansion and induced arterial hypertension in which there was reversal of neurological symptoms in $75 \%$. He found neurological improvement to be permanent in $74 \%$ and temporary in $7 \% .{ }^{99}$ As intravascular volume is expanded, patients may undergo a secondary diuresis which can make artificial elevation of the pulmonary capillary wedge pressure difficult. Use of low-dose vasopressin can help minimise the diuresis and help maintain an elevated intravascular fluid volume. Hypervolumetric and hypertensive therapy is continued until the neurological symptoms resolve or complications from therapy require re-evaluation of the risk/benefit ratio of continuing this type of treatment. Complications of hyperdynamic therapy include pulmonary oedema, congestive heart failure, brain oedema, hypertensive cerebral haemorrhage, systemic complications of prolonged vasopressor use, and myocardial infarction. Contraindications to hyperdynamic therapy include cerebral oedema, cerebral infarction, pulmonary oedema, adult respiratory distress syndrome, and increased intracranial pressure. ${ }^{144}$

When hyperdynamic therapy has proven unsuccessful or is contraindicated, we have found other less established manoeuvres helpful. We have found selective intra-arterial infusion of papaverine hydrochloride $(300 \mathrm{mg}$ over 1 hour) into the symptomatic vascular territory to be extremely useful in reversing angiographic vasospasm in some patients. The results of this therapy can be clinically dramatic, but in a similar fashion may be extremely fleeting or completely unsuccessful.
Further investigation needs to be performed to clarify the role of intra-arterial infusions of vasodilator substances for treatment of cerebral vasospasm. Anecdotal reports agree with our experience in the limited number of patients who have had this therapy. ${ }^{145} 146$

Another potentially useful adjunct in the treatment of posthaemorrhagic cerebral vasospasm is transluminal balloon angioplasty of the large intracranial vessels. A number of investigators have reported encouraging results with the use of this technique in vasospasm treatment. ${ }^{145}$ 147-149 $^{14}$ We have also witnessed marked improvement in cerebral circulation following transluminal angioplasty. We have also seen fatal complications of this technique due to vessel rupture and perforation. Linskey reported a fatal SAH that was produced by rupture of residual aneurysm neck by the angioplasty catheter. ${ }^{150}$ The use of such adjunctive treatment modalities should be undertaken with caution until further safety and efficacy of these procedures is more clearly understood.

\section{Management after hospital discharge}

Patients that have survived SAH and are ultimately discharged from the hospital require close follow up care to detect and treat latent complications. Communicating hydrocephalus may develop following discharge and may be manifest by increasing headache, lethargy, confusion, or regression of a previously improving neurological status. Occasionally fluid and electrolyte disturbances do not become evident until after discharge, and may only be suspected with a patient history of abnormal fluid intake coupled with mental status changes.

Seizures following SAH occur in a small number of patients. There is no evidence that seizures during the initial haemorrhage are likely to persist or recur later. Patients in our practice suffering SAH are usually placed on prophylactic anticonvulsants when they present to the hospital, and are maintained on anti-seizure medications for approximately six months postoperatively. Hart was unable to demonstrate the benefit of prophylactic anticonvulsant therapy after acute SAH. ${ }^{33}$ The most important risk factors determining the development of a seizure disorder are poor neurological grade and focal neurological deficits. Our belief is that postoperative seizures are socially stigmatising to such an extent that prophylactic anticonvulsant therapy for six months is of potential benefit with very little risk of side effects.

Because latent complications may develop, our pattern is to follow patients on a monthly basis following discharge with CT scans and laboratory testing as necessary. Patients are weaned from anticonvulsants approximately six months postoperatively and are followed with clinic visits until they are neurologically stable for one year.

\section{Conclusions}

The condition known as subarachnoid haemorrhage is a complex medical event that 
affects a significant number of people each year. The causes can be multifactorial, but are most commonly related to bleeding from an existing cerebral aneurysm. Many patients do not survive the initial SAH, and the optimal treatment for patients that come to diagnosis and treatment remains controversial. Diagnostic imaging techniques have significantly advanced over the past 10 years, although CT scanning and angiography remain the diagnostic procedure of choice. Controversy continues over the optimal time to perform aneurysm surgery following SAH. There does not appear to be any significant difference in overall patient outcome with early compared to delayed aneurysm surgery. Early surgery and antifibrinolytic medication can prevent rebleeding, but add to the management morbidity of acutely ill SAH patients. Delayed cerebral ischaemia continues to be a major cause of morbidity in SAH patients, despite medical and surgical adjuncts such as calcium channel blockers, hyperdynamic hypervolumetric therapy, infusion of intra-arterial vasodilators, transluminal angioplasty, and use of intraoperative thrombolytic drugs. Induced hypertension and volume expansion is the most reliable method of treating symptomatic vasospasm at the present time. In spite of therapeutic and surgical advances over the past two decades, a percentage of SAH patients will ultimately succumb or be neurologically injured, as long as $\mathrm{SAH}$ remains a condition that is not widely preventable.

Physicians who diagnose and manage patients with acute SAH would be well advised to keep up with the ever-changing developments in the management of this ubiquitous and catastrophic condition that may strike healthy and unsuspecting individuals at any time.

1 Clemente CD. Anatomy, a regional atlas of the human body, 3rd ed. Baltimore; Urban and Schwarzenberg, 1987:572-3.

2 Liliequist B. The subarachnoid Cisterns. An anatomic and Roentgenologic study. Acta Radiol (Stockholm) 1959;suppl:185.

3 Haines DE, Harkey HL, Al-Mefty O. The "subdural" space: a new look at an outdated concept. Neurosurg 1993;32:111-20.

4 Sahs A, Perret GE, Locksley HB, Nishioka H. Intracranial aneurysms and subarachnoid hemorrhage. Philadelphia: J B Lippincott, 1969.

5 Shokichi U, Masumichi I, Munesuke S, Masayoshi S. Subarachnoid hemorrhage as a cause of death in Japan. $Z$ Rechtsmed 1973;72:151-60.

6 Levy LE, Rachman L, Castle WM. Spontaneous primary subarachnoid hemorrhage in Rhodesian Africans. Afr $\mathcal{F}$ Med Sci 1973;4:77-86.

7 Locksley HB. Report on the cooperative study of intracranial aneurysms and subarachnoid hemorrhage,
Sect 5, P1. Natural history of subarachnoid hemorrhage, intracranial aneurysms, and arteriovenous malrhage, intracranial aneurysms, and arterio

8 Talbot S. Epidemiological features of subarachnoid and cerebral haemorrhages. Postgrad Med $₹$ 1973;49:300-4.

9 Crompton MR. The coroner's cerebral aneurysm: changing animal. f Forensic Sci Soc 1975;15:57-65.

10 Murphy JP. Subarachnoid hemorrhage; intracranial aneurysm. Cerebrovascular disease. Chicago: Year Book, 1954:199-241.

11 Ohno Y. Biometeorologic studies on cerebrovascular diseases. I. Effects of meteorologic factors on the death from cerebrovascular accident. $f_{p n}$ Circ $\mathcal{f}$ 1969; 33:1285-98.

12 Ohno Y. Biometeorologic studies on cerebrovascular diseases. II. Seasonal observation on effects of meteorologic factors on the death from cerebrovascular accident. Fpn Circ f 1969;33:1299-308.
13 Ohno Y. Biometeorologic studies on cerebrovascular diseases. III. Effects by the combination of meteorologic changes on the death from cerebrovascular accident $f_{p}$ Circ f 1969;33:1309-14.

14 Locksley HB. Natural history of subarachnoid hemorrhage, intracranial aneurysms and arteriovenous malformations. Pt I. In: Sahs AL, Perret GE, Locksley $\mathrm{HB}$, Nishioka $\mathrm{H}$, eds. Intracranial aneurysms and subarachnoid hemorrhage. A Cooperative study. Philadelphia: Lippincott 1969:37-57.

15 Freytag E. Fatal rupture of intracranial aneurysms Survey of 250 medicolegal cases. Arch Pathol 1966; 81:418-24.

16 Pakarinen $S$. Incidence, aetiology, and prognosis of primary subarachnoid hemorrhage. Acta Neurol Scand 1967;29:Suppl 1-128.

17 Locksley HB. Natural history of subarachnoid hemorrhage, intracranial aneurysms and arteriovenous malformations. Part II. In: Sahs AL, Perret GE, Locksley $\mathrm{HB}$, Nishioka $\mathrm{H}$, eds. Intracranial aneurysms and subarachnoid hemorrhage. A Cooperative Study. Philadelphia: Lippincott, 1969:58-108.

18 Sahs AL. Randomized treatment study. Introduction. In: Sahs AL, Nibbelink DW, Turner JC, eds. Aneurysmal Subarachnoid Hemorrhage. Report of the Aneurysmal Subarachnoid Hemorrhage. Report of the
Cooperative Study. Baltimore: Urban and Cooperative Study. Baltim

19 Stehbens WE. Subarachnoid hemorrhage. Pathology of the cerebral blood vessels. St Louis CV Mosby, 1972: 252-83.

20 Adams HP, Jergenson DD, Sahs AL. Pitfalls in the recognition of subarachnoid hemorrhage. $\mathfrak{F A M} A 1980$ 244:794-6.

21 Leblanc $R$. The minor leak preceding subarachnoid hemorrhage. $\mathcal{f}$ Neurosurg 1987;66:35-9.

22 Leblanc $R$, Winfield JA. The warning leak in subarachnoid hemorrhage and the importance of its early diagnosis. Can Med Assoc F 1984;131:1235-6.

23 Calvert JM. Premonitory symptoms and signs of subarachnoid haemorrhage. Med f Aust 1966;53:651-7.

24 Richardson JC, Hyland HH. Intracranial aneurysm. A clinical and pathological study of subarachnoid and intracerebral hemorrhage caused by berry aneurysms. Medicine 1984;20:1-83.

25 Berman AJ. The problem of the intracranial aneurysm. Angiology 1958;9:136-53.

26 Gillingham FJ. The management of ruptured intracranial aneurysm. Ann Roy Coll Surg 1958;23:89-117.

27 Shields CB. Current trends in management of cerebral aneurysms. F Kentucky Med Assoc 1977;75:529-35.

28 Kassell NF, Kongable GL, Torner JC, Adams HP, Mazuz H. Delay in referral of patients with ruptured aneurysms to neurosurgical attention. Stroke 1985;16: 587-90.

29 Kassell NF, Torner JC, Haley C, et al. The international cooperative study on the timing of aneurysm surgery. Part I: Overall management results. $\mathcal{F}$ Neurosurg Part I: Overall

30 Ito Z, Matsuoka S, Moriyama T, et al. Factors related to level of consciousness in the acute stage of ruptured intracranial aneurysms. Brain Nerve (Tokyo) 1975; 27:895-901.

31 Austin DC. A review of intracranial aneurysms. Henry Ford Hosp Med Bull 1964;12:251-71.

32 Fisher CM. Clinical syndromes in cerebral thrombosis, hypertensive hemorrhage, and ruptured saccular aneurysm. Clin Neurosurg 1975;22:117-47.

33 Hart RG, Byer JA, Slaughter JR, et al. Occurrence and implications of seizures in subarachnoid hemorrhage due to ruptured intracranial aneurysms. Neurosurgery 1981;8:417-21.

34 Sarner M, Rose FC. Clinical presentation of ruptured intracranial aneurysm. I Neurol Neurosurg Psychiatry 1967;30:67-70

35 Tsementzis SA, Williams A. Ophthalmological signs and prognosis in patients with a subarachnoid hemorrhage. Neurochirurgia 1984;27:133-5.

36 Kendall BE, Lee BC, Claveria E. Computerized tomography and angiography in subarachnoid haemorrhage. $B R \mathcal{F}$ Radiol 1976;49:4873-501.

37 Liliequist B, Lindquist $M$, Valdimarsson E. Computed tomography and subarachnoid hemorrhage. Neuroradiology 1977;14:21-6.

38 Modesti LM, Binet EF. Value of computed tomography in the diagnosis and management of subarachnoid hemorrhage. Neurosurgery 1978;3:151-6.

39 Scotti G, Ethler R, Melancon D, et al. Computed tomography in the evaluation of intracranial aneurysms and subarachnoid hemorrhage. Radiology 1977;123: 85-90.

40 Weir B, Miller J, Russell D. Intracranial aneurysms: A clinical, angiographic, and computerized tomographic study. Can $¥$ Neurol Sci 1977;4:99-105.

41 Fisher CM, Kistler JP, Davis JM. Relation of cerebral vasospasm to subarachnoid hemorrhage visualized by computerized tomographic scanning. Neurosurgery 1980;6:1-9.

42 Duffy GP. Lumbar puncture in spontaneous subarachnoid haemorrhage. $B M \mathcal{F} 1982 ; 285: 1163-4$

43 Sicard J-A. Chromodiagnostid cu liquide céphalorachidien dans les hémorragies du névraxe. Valeur de la teinte jaunatre. CR Soc Biol 1901;53:1050-3.

44 Milian G, Chiray. Méningite á pneumocoques. Zanthochromie du liquide céphal-rachidien. Bull Soc Anat Paris 1902;4:550-2. 
45 Froin G. Les Hémorragies Sous-Arachnoidiennes et le Mécanisme de l'Hématolyse en général. Paris: Steinheil, 1904

46 Collier J, Adie WJ. Cerebral vascular lesions. In: Price FW, ed. A textbook of the practice of medicine. London: Henry Frowde and Hodder and Stoughton, 1922: 1348-65.

47 Symondo CP. Spontaneous subarachnoid haemorrhage. $Q \mathcal{F}$ Med 1924-25;18:93-122.

48 Greenfield JG, Carmichael EA. The cerebrospinal fluid in clinical diagnosis. London, Macmillan, 1925:50-2.

49 Barrows LJ, Hunter FT, Banker BQ. The nature and clinical significance of pigments in the cerebrospinal fluid. Brain 1955;78:59-80.

50 Bramwell E. The etiology of recurrent ocular paralysis (including periodic ocular paralysis and ophthalmo-
plegic migraine). Edinburgh Med $\mathscr{f} 1933 ; 40: 209-81$.

51 Botterell EH, Lougheed WM, Scott JW, et al. Hypothermia, and interruption of carotid, or carotid and vertebral circulation in the surgical management of intracranial aneurysms. F Neurosurg 1956;13:1-42.

52 Lougheed WM, Marshall BM. Management of aneurysms of the anterior circulation by intracranial procedures. In: Youmans JR, ed. Neurological surgery vol 2. Philadelphia: Saunders, 1973:731-67.

53 Hunt WE, Hess RM. Surgical risk as related to time of intervention in the repair of intracranial aneurysms. f Neurosurg 1968;28:14-20.

54 Hunt WE, Kosnik EJ. Timing and perioperative care in intracranial aneurysm surgery. Clinical Neurosurg 1974; 21:79-89.

55 Hunt WE. Grading of patients with aneurysms. Letter to the Editor, $\mathcal{F}$ Neurosurg $1977 ; 47: 13$

56 Nibbelink DW, Torner J, Henderson WG. Intracranial aneurysms and subarachnoid hemorrhage. Stroke 1977; 8:202-18.

57 Hesselink JR. Investigation of intracranial aneurysm. In: Fox $\mathrm{JL}$, ed. Intracranial aneurysms, vol 1. New York: Springer-Verlag. 1983:497-548.

58 Teal JS, Wade PJ, Bergeron RT, et al. Ventricular opacification during carotid angiography secondary to rupture of intracranial aneurysm. Radiology 1973;106: 581-3.

59 Vines FS, Davis DO. Rupture of intracranial aneurysm at angiography. Radiology 1971;99:353-4.

60 Goldstein SL. Ventricular opacification secondary to rupture of intracranial aneurysm during angiography. f Neurosurg 1967;27:265-7.

61 Hackney DB, Lesnick JE, Zimmerman RA, Grossman RI, Goldberg HI, Bilaniuk LT. MR identification of bleeding site in subarachnoid hemorrhage with multiple intracranial aneurysms. F Comput Assist Tomog 1986;10:878-80.

62 Friedman AH. Subarachnoid hemorrhage of unknown etiology. In: Wilkins RH, Rengachary SS, eds. Neurosurgery update II, New York: McGraw-Hill, 1991:73-7.

63 Nishioka H, Torner JC, Graf CJ, et al. Cooperative study of intracranial aneurysms and subarachnoid hemorrhage: A longterm prognostic study. III. Subarachnoid rhage: A longterm prognostic study. III. Subarachnoid hemorrhage of und

64 Perret $G$, Nichioka $H$. Cerebral angiography: Diagnostic value and complications of carotid and vertebral angiography. In: Sahs AL, ed. Intracranial aneurysms and subarachnoid hemorrhage: a cooperative study. Philadelphia: Lippincott, 1969:109-24.

65 Forster DMC, Steiner L, Hakanson S. The value of repeat panangiography in cases of unexplained subarachnoid hemorrhage. $\mathcal{f}$ Neurosurg 1978;48:712-6.

66 Biller J, Toffol GJ, Kassell NF, et al. Spontaneous subarachnoid hemorrhage in young adults. Neurosurgery 1987;21:664-7.

67 Juul R, Fredricksen TA, Ringkjob R: Prognosis in subarachnoid hemorrhage of unknown etiology. $\Im$ Neurosurg 1986;64:359-62

68 Giombini S, Burzzone MG, Pluchino F. Subarachnoid hemorrhage of unexplained cause. Neurosurgery 1988; 22:313-6.

69 Suzuki S, Kayama T, Sakurai Y, et al. Subarachnoid hemorrhage of unknown cause. Neurosurgery 1987;21: 310-3.

70 Alexander MSM, Dias PS, Uttley D. Spontaneous subarachnoid hemorrhage and negative cerebral panangiography: Review of 140 cases. $\mathcal{f}$ Neurosurg 1986; 64:537-42.

71 Andrioli GC, Salar G, Rigobello L, et al. Subarachnoid haemorrhage of unknown etiology. Acta Neurochir (Wien) 1979;48:217-21.

72 Béguelin C, Seiler R. Subarachnoid hemorrhage with normal cerebral panangiography. Neurosurgery 1983;13: 409-11.

73 Brismar J, Sundbarg G. Subarachnoid hemorrhage of unknown origin: Prognosis and prognostic factors. f Neurosurg 1985;63:349-54.

74 Nishioka H, Torner JC, Graf CJ, Kassell NF, Sahs AL, Goettler LC. Cooperative study of intracranial aneurysms and subarachnoid hemorrhage: A long-term prognostic study. II. Ruptured intracranial aneurysms prognostic study. II. Ruptured intracranial aneurysms
managed conservatively. Arch Neurol 1984;41:1142-6.

75 Stober T, Emde H, Anstatt T, et al. Blood distribution in computer cranial tomograms after subarachnoid hemorrhage with and without an aneurysm on angiography. Eur Neurol 1985;24:319-23.

76 Smith RR, Miller JD. Pathophysiology and clinical evaluation of subarachnoid hemorrhage. In: Youmans JR. Neurological Surgery. Philadelphia: WB Saunders, 1990: 1644-60.

77 Margolis MT, Newton TH. Methamphetamine ("speed") arteritis. Neuroradiology 1971;2:179-82.

78 Weir B. Medical, neurologic, and ophthalmologic aspects of aneurysms, Pt 2: Neurology of aneurysms and subarachnoid hemorrhage. Aneurysm affecting the nervous system. Baltimore: Williams and Wilkins, 1987;74-83.

79 Bohn E, Hugosson R. Experiences of surgical treatment of 400 consecutive ruptured cerebral aneurysms. Acta Neurochir 1978;49:33-43.

80 Modesti LM, Binet EF. Value of computed tomography in the diagnosis and management of subarachnoid in the diagnosis and management of
hemorrhage. Neurosurgery 1978;3:151-6.

81 Gijn JV, Hijdra A, Wijdicks EF, Vermeulen M, Crevel HV. Acute hydrocephalus after aneurysmal subarachnoid hemorrhage. ₹ Neurosurg 1985;63:355-62.

82 Bogdahn U, Lau W, Hassel W, Gunreben G, Mertens HG, Brawanski A. Continuous-pressure controlled, external ventricular drainage for treatment of acute hydrocephalus-Evaluation of risk factors. Neurosurg 1992;31:898-904.

83 Pakarinen S. Incidence, aetiology, and prognosis of primary subarachnoid hemorrhage: A study based on 589 cases diagnosed in a defined urban population during a defined period. Acta Neurol Scand 1967;43:(Suppl 29): 1-128.

84 Chason IL, Hindman WM. Berry aneurysms of the circle of Willis: Results of a planned autopsy study. Neurology 1958;8:41-4.

85 Nakagawa F, Kobayashi S, Takemae T, Sugita K. Aneurysms protruding from the dorsal wall of the internal carotid artery. $f$ Neurosurg 1986;65:303-8.

86 Forbus WD. On the origin of the miliary aneurysms of the superficial cerebral arteries. Bull fohns Hopkins Hosp 1930;47:239-84

87 Early CB, Fink LH. Some fundamental applications of the law of LaPlace in neurosurgery. Surg Neurol 1976;6:185-9.

88 Graf CJ. Prognosis for patients with nonsurgically treated aneurysm. Analysis of the cooperative study of intracranial aneurysm and subarachnoid hemorrhage. intracranial aneurysm and Neurosurg $1971 ; 35: 438-43$.

89 McCormick WF, Rosenfield DB. Massive brain hemorrhage. A review of 144 cases and an examination of their causes. Stroke 1973;4:946-54.

90 Drake CG. Giant intracranial aneurysms: Experience with surgical treatment in 174 patients. Clin Neurosurg 1979;26:12-95.

91 Sundt TM, Piepgras DG. Surgical approach to giant intracranial aneurysm. Operative experience with 80 cases. F Neurosurg 1979;51:731-42.

92 Crompton MR. Mechanism of growth and rupture in cerebral berry aneurysms. BMF 1966;1:1138-42.

93 Crompton MR. The natural history of cerebral berry aneurysms. Am Heart $\mathcal{F}$ 1976;73:567-9.

94 Stehbens WE. Aneurysms and anatomical variation of cerebral arteries. Arch Pathol 1953;75:45-64.

95 DuBoulay GH. The significance of loculation of intracranial aneurysms. Bull Schweiz Akad Med Wiss intracranial an

96 Nehls DG, Flom RA, Carter LP, Spetzler RF. Multiple intracranial aneurysms: Determining the site of rupture. F Neurosurg 1985;63:342-8.

97 Heiskanen $O$. The identification of ruptured aneurysm in patients with multiple intracranial aneurysms. Neurochirurgia (Stuttg) 1965;8:102-7.

98 Pool JL, Potts DG. Aneurysms and arteriovenous anomalies of the brain. Diagnosis and treatment. New York: Harper and Row, 1965.

99 Kassell NF, Peerless SJ, Durward QJ, et al. Treatment of ischemic deficits from vasospasm with intravascular volume expansion and induced arterial hypertension. Neurosurgery 1982;11:337-43.

100 Swift DM, Solomon RA. Unruptured aneurysms and postoperative volume expansion. $\mathcal{f}$ Neurosurg 1992;

101 Yasargil MG. Unoperated cases. Microneurosurgery. Stuttgart: Georg Thieme Verlag, 1984:329-30.

102 Bailes JE, Spetzler RF, Hadley MN, Baldwin HZ. Management morbidity and mortality of poor-grade aneurysm patients. $\mathcal{F}$ Neurosurg 1990;72:559-66.

103 Norlen G, Olivercrona $H$. The treatment of aneurysms of the circle of Willis. $\mathcal{F}$ Neurosurg 1953;10:404-15.

104 Weir B, Aronyk K. Management and postoperative mortality related to time of clipping for supratentorial aneurysms. A personal series. Acta Neurochir 1982; 63:135-9.

105 Wilkins RH. The role of intracranial arterial spasm in the timing of operations for aneurysm. Clin Neurosurg 1977;24:185-207.

106 Kassell NF, Torner JC, Jane JA, et al. The international cooperative study on the timing of aneurysm surgery. Part 2: Surgical results. F Neurosurg 1990;73:37-47.

107 Medlock MD, Dulebohn SC, Elwood PW. Prophylactic hypervolemia without calcium channel blockers in early aneurysm surgery. Neurosurg 1992;30;12-6.

108 Tomer JC Kossell NF Wallace RB, Adams HP. Preoperative prognostic factors for rebleeding and survival in aneurysm patients receiving antifibrinolytic therapy: Report of the cooperative aneurysm study. Neurosurgery 1981;9:506-13.

109 Pickard JD, Murray GD, Illingworth R, et al. Effect of 
oral nimodipine on cerebral infarction and outcome after subarachnoid haemorrhage: British Aneurysm Nimodipine Trial. $B M \Im$ 1989;298:636-42.

110 Allen GS, Ahn HS, Preziosi TJ, et al. Cerebral arterial spasm: A controlled trial of nimodipine in patients with subarachnoid hemorrhage. $N$ Engl 7 Med 1983;308: 619-24.

111 Mee E, Dorrance D, Lowe D, et al. Controlled study of nimodipine in aneurysm patients treated early after nimodipine in aneurysm patients treated early after

112 Pretruk KC, West M, Mohr G, et al. Nimodipine treatment in poor grade aneurysm patients. Results of treatment in poor grade aneurysm patients. Results of a multicenter double-blind

113 Kassell NF, Torner JC, Adams HP. Antifibrinolytic therapy in the acute period following aneurysmal subarachnoid hemorrhage: Preliminary observations from the cooperative aneurysm study. F Neurosurg 1984;61: 225-30.

114 Adams HP Jr. Current status of antifibrinolytic therapy of patients with subarachnoid hemorrhage. Stroke 1982;13:256-9.

115 Burchiel JK, Hoffman JN, Bakay FAR. Quantitative determination of plasma fibrinolytic activity in patients with ruptured intracranial aneurysms who are receiving with ruptured intracranial aneurysms who are receiving Eaminocaproic acid: Relationship of possible complica-
tions of therapy to the degree of fibrinolytic inhibition. tions of therapy to the deg
Neurosurg 1984;14:57-63.

116 Adams HP, Nibbelink DW, Torner JC, Sahs AL Antifibrinolytic therapy in patients with aneurysmal subarachnoid hemorrhage. In: Sahs AL, Nibbelink DW, Torner JC, eds. Aneurysmal subarachnoid hemorrhage. Report of the Cooperative Study. Baltimore: Urban Schwarzenberg, 1981:331-9.

117 Park BE. Spontaneous subarachnoid hemorrhage complicated by communicating hydrocephalus: Epsilon amino caproic acid as a possible predisposing factor. Surg Neurol 1979;11:73-80.

118 Rosenorn J, Eskesen V, Schmidtk, et al. The risk of rebleeding from ruptured intracranial aneurysms. rebleeding from ruptured

119 Kassell NF, Torner JC. Aneurysmal rebleeding: A preliminary report from the cooperative study. Neurosurgery 1983;13:479-81.

120 Paine JT, Batjer HH, Samson DS. Intraoperative ventricular puncture-Technical note. Neurosurgery 1988 22:1107-9.

121 Mizukami M, Kawase T, Usami T, et al. Prevention of vasospasm by early operation with removal of subarachnoid blood. Neurosurgery 1982;10:301-7.

122 Sano K, Saito I. Early operation and washout of blood clots for prevention of cerebral vasospasm. In: Wilkins RH, ed. Cerebral arterial spasm. Baltimore: Williams and Wilkins, 1980:510-3.

123 Taneda $M$. Effect of early operation for ruptured aneurysm on prevention of delayed ischemic sympaneurysm on prevention of delaye

124 Batjer HH, Samson D. Intraoperative aneurysmal rupture: Incidence, outcome, and suggestions for surgical management. Neurosurgery 1986;18:701-6.

125 Yasargil MG. Microneurosurgery, vol 2. Stuttgart, George Thieme Verlag, 1984:58-9.

126 Giannotta SL, Oppenheimer JH, Levy ML, Zelman V. Management of intraoperative rupture of aneurysm without hypotension. Neurosurgery 1991;28:531-6.

127 Batjer HH, Frankfurt AI, Purdy PD, et al. Use of Etomidate, temporary arterial occlusion, and intraoperative angiography in surgical treatment of large and

128 Mizukami M, Kawase T, Usame I, Tazawa T. Prevention of vasospasm by early operation with removal of subarachnoid blood. Neurosurgery 1981;10: removal

129 Teneda $M$. Effect of early operation for ruptured aneurysms on prevention of delayed ischemic symptoms. F Neurosurg 1982;57:622-8.

130 Mizoi K, Yoshimoto T, Fujiwara S, Sugawara T, Takahashi A, Koshu K. Prevention of vasospasm by clot removal and intrathecal bolus injection at tissuetype Plasminogen Activator: Preliminary report. Neurosurg 1991;28:807-13.

131 Findlay JM, Weir BKA, Steinke D, Tanabe T, Gordon $P$, Grace M. Effect of intrathecal thrombolytic therapy on subarachnoid clot and chronic vasospasm in a primate model of SAH. $f$ Neurosurg 1988;69: in a prim.

132 Seifert V, Eisert WG, Stolke D, Goetz C. Efficacy of single intracisternal bolus injection of recombinant tissue plasminogen activator to prevent delayed tissue plasminogen activator to prevent delayed cerebral vasospasm after experimental

133 Findlay JM, Weir RIIA, Kassell NF, Disney LB, Grace MGA. Intracisternal recombinant tissue plasminogen activator after aneurysmal subarachnoid hemorrhage. f Neurosurg 1991;75:181-8.

134 Takaku A, Tanaka S, Mori T, Suzuki J. Postoperative complications in 1,000 cases of intracranial aneurysms. Surg Neurol 1979;12:137-44.

135 Yamamoto I. Early operation for ruptured intracranial anerysms: comparative study with computerized tomography. Presented at the 32nd Annual Meeting, Congress of Neurological Surgeons, Toronto, 1982.

136 Heros R, Zarvas N, Varsos V. Cerebral vasospasm after subarachnoid hemorrhage: An update. Ann Neurol 1983;14:599-608.

137 Ropper AH, Zervas NT. Outcome 1 year after SAH from cerebral aneurysm. Management, morbidity, mortality, and functional status in 112 consecutive good risk patients. $\mathcal{F}$ Neurosurg 1984;60:909-15

138 Fisher CM, Roberson GH, Ojemann RG. Cerebral vasospasm with ruptured saccular aneurysm-The clinical manifestations. Neurosurgery 1977:1:245-8.

139 Weir BK. Pathophysiology of vasospasm. Int Anesthesiol Clin 1982;10:39-43.

140 Pasqualin A, Rosta L, Da Pian R, Cavazzani P, Scienza $R$. Role of computed tomography in the management of vasospasm after subarachnoid hemorrhage. Neurosurgery 1984;15:344-53.

141 Kistler IP, Crowell RM, Davis KR, Heros $R$, Ojemann RG, Zervas T, Fisher CM. The relation of cerebral va, Zervas T, Fisher CM. The relation of cerebral vasospasm to the extent and location of subarachnoid
blood visualized by CT scan. A prospective study. blood visualized by CT scar

142 Symon L. Disordered cerebro-vascular physiology in aneurysmal subarachnoid haemorrhage. Acta Neurochir (Wien) 1979;41:7-22.

143 Pritz MB, Giannotta SL, Kindt GW, McGillicuddy JE, Prager RL. Treatment of patients with neurological deficits associated with cerebral vasospasm by intravascular volume expansion. Neurosurgery 1978;3:364-8.

144 Shimoda $M$, Oda S, Tsugane R, Sato O. Intracranial complications of hypervolemic therapy in patients with a delayed ischemic deficit attributed to vasospasm. a delayed ischemic deficit

145 Kaku Y, Yonekawa Y, Tsukahara T, Kazekawa K. Superselective intra-arterial infusion of papaverine for the treatment of cerebral vasospasm after subarachnoid hemorrhage. $\mathcal{f}$ Neurosurg 1992;77:842-7.

146 Kassell NF, Helm G, Sommons N, Phillips CD, Cail WS. Treatment of cerebral vasospasm with intraarterial papaverine. $\mathcal{f}$ Neurosurg 1992;77:848-52.

147 Higashida RT, Halbach VV, Cahan LD, et al. Transluminal angioplasty for treatment of intracranial arterial vasospasm. $\mathcal{F}$ Neurosurg 1989;71:648-53.

148 Newell DW, Eskridge JM, Maybery MR, et al. Angioplasty for the treatment of symptomatic vasospasm following subarachnoid hemorrhage. $尹$ Neurosurg 1989;71:654-60

149 Zubkov YN, Nikiforov BM, Shustin VA Balloon catheter technique for dilatation of constricted cerebral arteries after aneurysmal SAH. Acta Neurochir 1984; 70:65-79.

150 Linskey ME, Horton JA, Rao GR, Yonas H. Fatal rupture of the intracranial carotid artery during transluminal angioplasty for vasospasm induced by subarachnoid hemorrhage. F Neurosurg 1991;74:985-90. 